\title{
4D Modelling of Low Visibility Underwater Archaeological Excavations Using Multi-Source Photogrammetry in the Bulgarian Black Sea
}

\author{
Rodrigo Pacheco-Ruiz, Jonathan Adams, Felix Pedrotti
}

\begin{abstract}
This paper introduces the applicability of underwater photogrammetric survey within challenging conditions as the main tool to enhance and enrich the process of documenting archaeological excavation through the creation of $4 \mathrm{D}$ models. Photogrammetry was being attempted on underwater archaeological sites at least as early as the 1970s' and today the production of traditional 3D models is becoming a common practice within the discipline. Photogrammetry underwater is more often implemented to record exposed underwater archaeological remains and less so as a dynamic interpretative tool.

Therefore, it tends to be applied in bright environments and when underwater visibility is $>1 \mathrm{~m}$, reducing its implementation on most submerged archaeological sites in more turbid conditions. Recent years have seen significant development of better digital photographic sensors and the improvement of optical technology, ideal for darker environments. Such developments, in tandem with powerful processing computing systems, have allowed underwater photogrammetry to be used by this research as a standard recording and interpretative tool. Using multi-source photogrammetry (5, GoPro5 Hero Black cameras) this paper presents the accumulation of daily (4D) underwater surveys carried out in the Early Bronze Age (3,300 BC) to Late Ottoman (17th Century AD) archaeological site of Ropotamo in the Bulgarian Black Sea under challenging conditions $(<0.5 \mathrm{~m}$ visibility). It proves that underwater photogrammetry can and should be used as one of the main recording methods even in low light and poor underwater conditions as a way to better understand the complexity of the underwater archaeological record.
\end{abstract}

Keywords - 4D modelling, Black Sea, maritime archaeology, underwater photogrammetry, Bronze Age, low visibility.

\section{INTRODUCTION}

A MONG the methods of recording the structures, finds and features revealed by archaeological excavation, photography has long been obligatory, alongside the production of conventional drawn plans, profiles and sections. Indeed sometimes the techniques are merged and the rectification of stereophotographs, began to make their mark some decades ago. Under water, things were more challenging. Light absorption and the associated loss of colour and contrast at depth, exacerbated by any suspended particulate matter, presented a set of constraints that were not easily surmounted with the technology then available. This was certainly so for the first underwater photographer, Louis Boutan, who was in action in the 1890 s but was still the case when George Bass carried out the first professional underwater

Rodrigo Pacheco-Ruiz is with The Centre for Maritime Archaeology, University of Southampton, Highfield, Southampton, Great Britain SO17 1BF (e-mail: R.Pacheco-Ruiz@ soton.ac.uk).

Jonathan Adams and Felix Pedrotti are with The Centre for Maritime Archaeology, University of Southampton, Highfield, Southampton, Great Britain SO17 1BF archaeological excavation in 1960 [1]. This is why underwater photography became a challenging specialty, especially on archaeological sites where visibility tended to be low. This did not prevent people from trying to beat the conditions and photogrammetry was recognised as a technique of enormous potential for underwater recording as early as the 1970s' [2]. The excavation of the Tudor warship Mary Rose in the UK between 1971 and 1982 saw protracted experiments with cameras, mosaicking, 3D recording and an early attempt at 3D photogrammetric software [3], [4].

Since then two breakthroughs have revolutionised underwater photography and in particular the application of photogrammetric techniques on archaeological sites: The first was the development of digital photography, removing the limitation on the number of frames that could be acquired in a dive and of having to develop the film before seeing the results. More recently still are the breakthroughs in software. Proprietary photogrammetry packages have been available for many years but were either complex to use or did not provide the necessary accuracy. It is only in the last five years that software was developed that was both easy to use and which produced highly accurate results.

This paper presents an adaptation of photogrammetric recording tailored to the specific conditions of underwater archaeological excavation in limited visibility.

The site in question is Ropotamo, a sheltered bay on the coast of the Black Sea in Southern Bulgaria where evidence of maritime activity and habitation extend back into prehistory. The excavation was carried out as part of the Black Sea Maritime Archaeology Project (Black Sea MAP), a long term, international project addressing human response to environmental change in later prehistory. As well as the excavation in 2017 , the Black Sea MAP team carried out three seasons of offshore geophysical survey and geological sampling as well as the recording of 65 wreck sites in depths down to $2140 \mathrm{~m}$. The principal method of recording these wrecks was underwater photogrammetry and this furnished the team with extensive experience in acquiring imagery of sufficient quality, resolution and orientation to achieve successful 3D recordings of a series of internationally important wreck finds spanning 2,500 years of seafaring. It was this expertise that was turned to solving the problems of accurately recording the three-dimensional positions of structures and the three-dimensional relationships of objects. This not only had to be done in low visibility, sometimes less than $1 \mathrm{~m}$, but had to be done on a daily basis in order 
to keep pace with the progress made by the excavators. Adding time to the equation and thus creating high resolution fourth-dimensional models of the archaeological investigation process underwater.

\section{UNDERWATER ARCHAEOLOGICAL EXCAVATIONS}

The site of Ropotamo is a deeply stratified archaeological site that has shown a considerable amount of human activity reflected in an important accumulation of archaeological material dating back to the Early Bronze Age 5,300 BP until at least the 17th Century AD. The importance of the site has been obvious since the first archaeological excavations during the 1980s by Prof. Ivan Karayatov [5]. Once a settlement and later a harbour, Ropotamo is not only significant in terms of its archaeological record, but also for understanding how human societies dealt with climatic changes, in particular their reaction to relative sea level change.

Since 2015, the Black Sea Maritime Archaeology Project led by the University of Southampton's Centre for Maritime Archaeology has collected archaeological and palaeonvironmental data in the nearshore as well the offshore zones. The rationale was that by clarifying our understanding of the processes and chronology of Holocene climate change, this would increase our understanding of the effects this had on later prehistoric human populations in the area.

The offshore campaigns have witnessed the discovery of 65 new shipwrecks shedding new light on nearly 2,500 years of seafaring in the Black Sea, as far back as the late 5th Century BC. These datasets were enriched with, 92 sediment core samples taken from the nearshore, continental shelf and the continental slope, allowing the team to address long debated questions regarding the nature of inundation of the Black Sea after the last glacial maximum (LGM) approx. 22,000 years BP [6]-[13]. Ropotamo underwater excavations work as a research link between the minutiae of the archaeological evidence, the newly discovered shipwrecks and the rich palaeoenvironmental datasets collected so far. The aim was to record with the highest level of detail the palimpsest of human activities present in Ropotamo using high resolution 4D photogrammetric datasets.

The use of photogrammetry not only allowed for a millimetric recording of the excavations in time and space. It also presented new avenues of research as progress was monitored more actively during the intervention, rather than during post-processing. We believe therefore that this is the first time that an underwater excavation has successfully recorded daily temporal modifications, hence the fourth-dimension, to such a high level of detail and accuracy.

Our excavations at Ropotamo stem from the work of Ivan Karayotov [5] who identified the site's importance in the 1980 s as well as from the concentration of the archaeological material found within the first $20 \mathrm{~cm}$ of the seabed. Following a programme of marine geophysical survey a target area of 20 square metres was delineated within which two $5 \times 5 \mathrm{~m}$ trenches and subsequently excavated. The average depth of the archaeological site is 2.3 metres below contemporary Black Sea mean sea level (BSMSL), the excavation reached the Early Bronze Age layer at 5.7 metres.

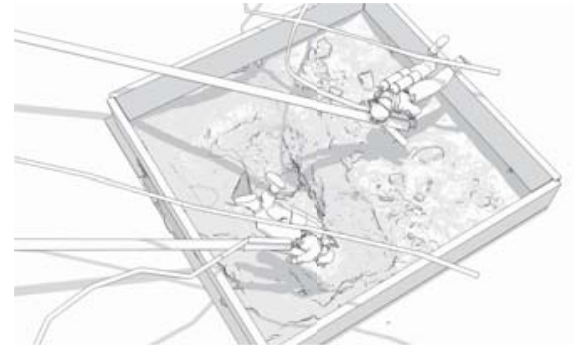

Fig. 1 Sketch of the excavation methodology showing both $5 \times 5 \mathrm{~m}$ trenches Trench 1 shows excavation techniques using undewater dredges. Trench 2 shows divers recording the excavation using photogrammetry (Image Rodrigo Pacheco-Ruiz)

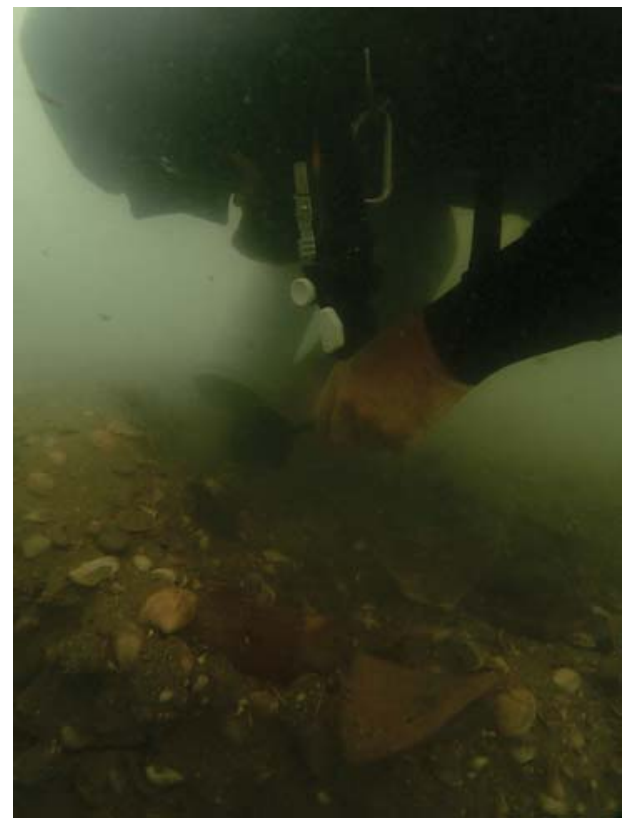

Fig. 2 Maritime archaeologist using an underwater dredge to carefully remove the loose sediments from the excavation under poor visibility (Photograph Johan Rönnby)

Due to the loose nature of the seabed it was decided to enclose the areas to be excavated within two $5 \times 5 \mathrm{~m}$ cofferdams to keep the excavation area free of seabed sediment contamination (Fig. 1). This was performed by trained maritime archaeologists with experience in scientific and commercial diving.

Underwater excavation utilised water-suction dredges, designed for archaeological use, where the dredge is used only for spoil removal. The excavators removing the sediments surrounding archaeological material with their hands or appropriate hand tools (Fig. 2). Once the excavators exposed the archaeological context, a team of underwater surveyors registered the $5 \times 5 \mathrm{~m}$ trenches using multi-source underwater photogrammetry.

\section{UNDERWATER CONDITIONS}

During the spring of 2017 an unusual bloom of Coccolithophores invaded the waters of the Black Sea (Fig. 3). This event adversely affected underwater visibility, turning the Ropotamo excavation into a challenging environment 


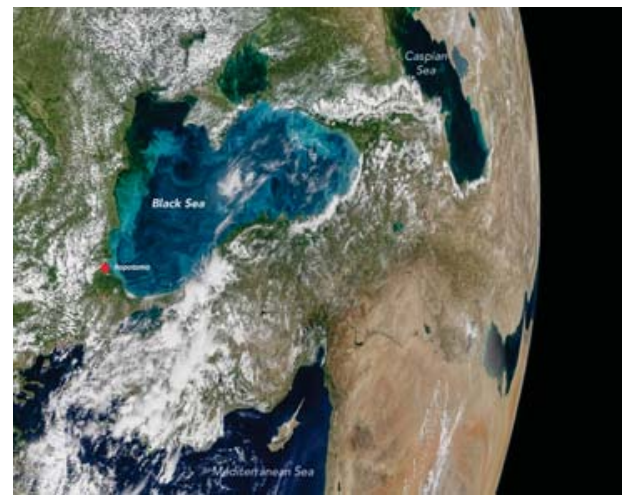

Fig. 3 On May 29, 2017, the Moderate Resolution Imaging Spectroradiometer (MODIS) on NASA's Aqua satellite captured the data for this image of an ongoing phytoplankton bloom in the Black Sea. The image is a mosaic, composed from multiple satellite passes over (Photograph NASA)

for underwater photography with an average of $<0.5 \mathrm{~m}$ of camera visibility. Whilst photogrammetry underwater is widely used when conditions are considerably greater than $0.5 \mathrm{~m}$ [14], [15] little is known about the applicability of this method in poor conditions. As the visibility improves producing photogrammetric models becomes progressively easier. The lack of light hinders the ability of capturing a sharp image of an object, crucial for producing good quality photogrammetric models. In turbid water artificial light from video lights or photographic strobes tends to generate back-scatter causing over-exposure and focusing problems. A more effective remedy is to reduce the camera to subject distance as was done in Ropotamo.

\section{Methodology}

The use of conventional single or double camera photogrammetric methodologies in these conditions would not have been sufficient to achieve the project's aims of recording each 25 square metre trench on a daily basis. As an example, Fig. 4a shows the angle of coverage when using a camera fitted with a $35 \mathrm{~mm}$ focal length lens. Alternatively, at $<$ $50 \mathrm{~cm}$ of visibility the surveyor has to be closer to the subject reducing the coverage and allowing for less overlap between photographs as seen in Fig. 4b.

As is well understood, photogrammetric coverage of a $3 \mathrm{D}$ object or scene requires a sufficient number of images with overlap between each adjacent pair. Whereas in air this can be achieved by moving the camera (or laser scanner) around the subject, gradually increasing coverage as if one were painting it with a spray gun, under water this is achieved by tracking the camera over and around the subject in a series of reciprocal, circular or spiral paths (Fig. 5). However, changes in the scene affect the results of the photogrammetric processing. In a dynamic underwater environment such as an active archaeological excavation it is difficult to maintain such visual stability. Sediment in the water column, gas bubbles, movement of flora and fauna, can all change the scene morphology during the course of even a short survey. These change apparent outline, hue and contrast of objects in the

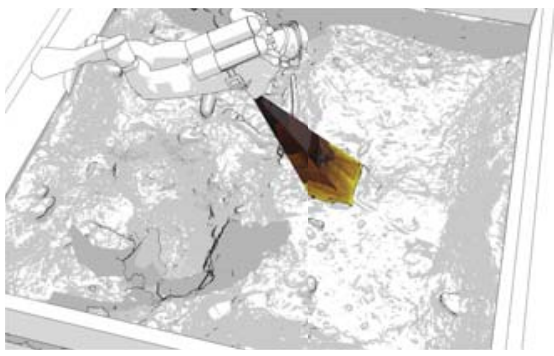

(a) $35 \mathrm{~mm}$ focal length of conventional DSLR field of view in $>50 \mathrm{~cm}$ visibility.

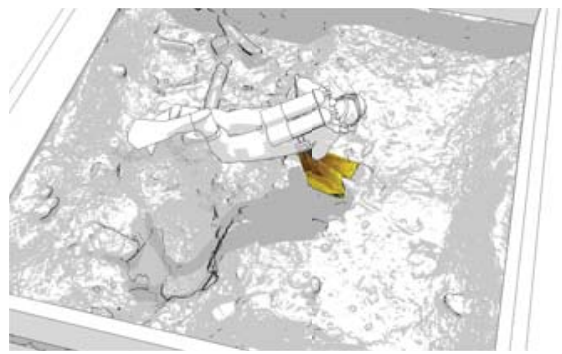

(b) $35 \mathrm{~mm}$ focal length of conventional DSLR field of view in $<50 \mathrm{~cm}$ visibility.

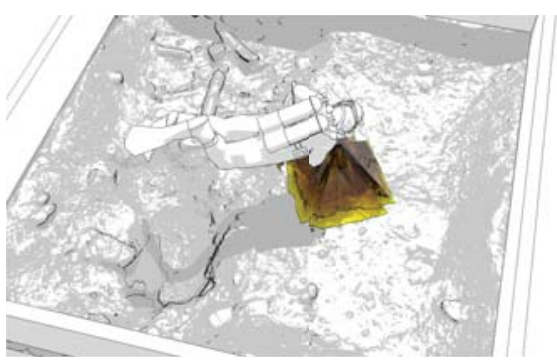

(c) $5 \mathrm{~mm}$ focal length using five GoPro HERO5 Black mounted on a $3 \mathrm{D}$ printer rig. The field of view represents visibility in $<50 \mathrm{~cm}$ conditions.

Fig. 4 Images showing the coverage of underwater photographic equipment in different visibility conditions. Lighter areas on the drawing's field of view represent objects within coverage (Images Rodrigo Pacheco-Ruiz)

scene and can result in datasets in which many of the images cannot be aligned.

To mitigate the potential problems of changes in the morphology of the scene it was decided to build a rig that was light enough for any diver to use underwater; capable of holding a number of cameras that could operate in low light conditions and capturing photographs at a distance of $<0.5 \mathrm{~m}$ - in this case five GoPro Hero 5 Black Edition cameras (Fig. 5). The design of such a rig was then printed in polilactide acid (PLA) material using a 3D printer and using the hinge system supplied with the cameras for attachment. A blueprint of the rig is shown in Fig. 6.

The five cameras are mounted as follows: An opposing pair facing forwards and backwards, $38^{\circ}$ down from the horizontal. Another pair similarly faces down to the left and right. The fifth camera faces vertically downwards. All the cameras face inwards, their angle of view ensuring coverage and overlap with each other. The placement and angle of the cameras on the rig was the best position to be used on cameras with a $3 \mathrm{~mm}$ focal length such as the GoPro model used. The mutual overlap 


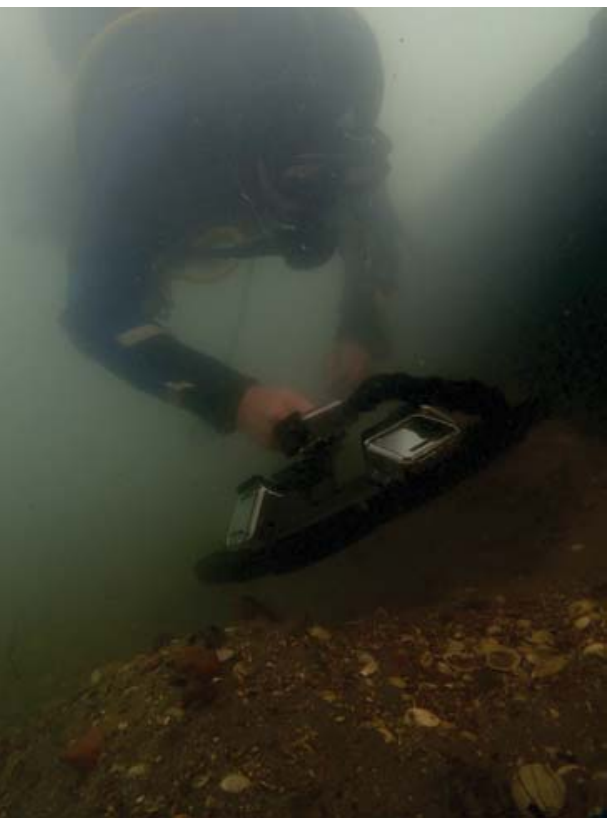

Fig. 5 Maritime archaeologist surveying underwater in $<0.5 \mathrm{~m}$ visibility conditions (Photograph Johan Rönnby)

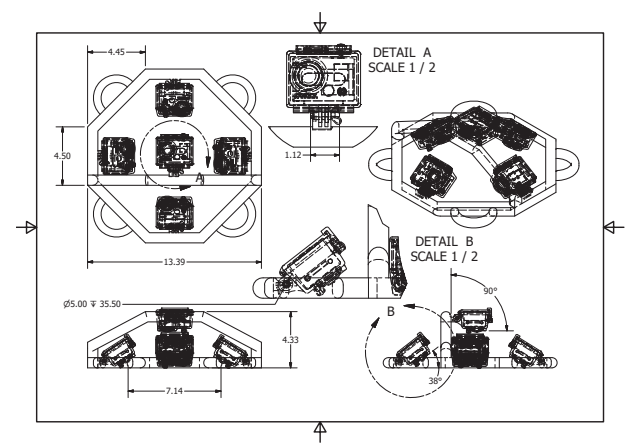

Fig. 6 Blueprint of the 3D printed hemispheric rig used for underwater photogrammetry. Details A and B in the image show the mounting point dimensions for a GoPro Hero 5 camera. All measurements are in millimetres (Image Rodrigo Pacheco-Ruiz and Felix Pedrotti)

in which the field of view (FOV) of each camera overlaps with all four others not only gives $100 \%$ coverage and substantial overlap but largely obviates the problems caused by changing scene morphology noted above.

\section{A. Survey Strategy}

Survey time and coverage were enhanced by using the $3 \mathrm{D}$ printed rig. The five cameras will simultaneously take a photograph with a resolution of $4000 \times 3000$ pixels every 2 seconds using the inbuilt 'time lapse' function of the cameras. The object was then fully surveyed from the top, front, rear, left and right allowing the operator to swim in a straight line rather than swimming around the object - as it is often the case with conventional underwater photogrammetric surveys. This method not only had the advantage of minimising the time of the photogrammetric survey, but also it helped the diver to maintain the survey heading and therefore avoiding confusion in low visibility conditions.

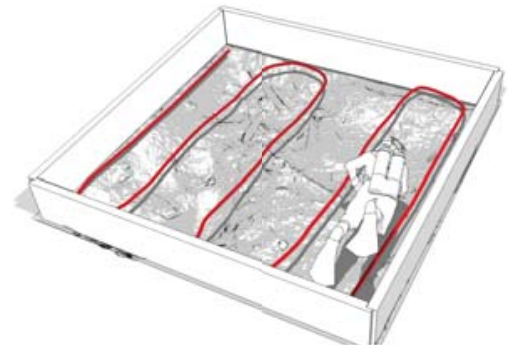

(a) Initial conventional transect survey. This method had the disadvantage of losing continuity with the bottom edge of the trench panels, essential reference for photographic alignment and a key element to geo-rectify the trench.

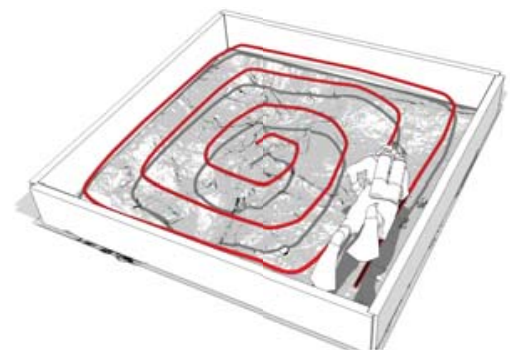

(b) The spiral method was the ideal survey trajectory in $<0.5 \mathrm{~m}$ visibility conditions as it kept more than $50 \%$ overlap between the images

Fig. 7 Sketches showing the coverage of underwater photographic equipment in different visibility conditions. Lighter areas on the drawing's field of view represent objects within coverage (Sketch Rodrigo Pacheco-Ruiz)

As this methodology was being tested during the campaign a number of trials were conducted to design an ideal survey trajectory. Initially, a transect trajectory was implemented: a diver operating the rig swam back and forth on designated parallel transects with the aim of collecting enough photographs to achieve more than $50 \%$ overlap between them (Fig. 7a). Whilst this method would have produced enough coverage in $>1 \mathrm{~m}$ underwater visibility conditions, it did not allow the panels delineating each trench to be sequentially mapped. This was important as the coffer dam, being exactly $5 \mathrm{~m}^{2}$, was used to geo-reference and scale the trenches as seen in the following section.

An alternative method was therefore needed for collecting photogrammetric datasets in $<0.5 \mathrm{~m}$ visibility. The most effective was to survey the area in a spiral pattern as seen in Fig. 7b. This system proved to be more successful in low visibility as there was an increased continuity between the images taken of the panelling structures and the adjacent archaeological context, which in turn facilitate the processing sequence and the image alignment in Agisoft Photo Scan Pro.

\section{Data Processing And Modelling}

On the day of each survey the photographs were transferred to the processing stations, two Dell Precision Tower7810 were used. The CPU processing power came from the 16 cores (2 x Intel(R) Xeon(R) CPU E5-2699 v3 @ 2.30 Ghz) with additional 192 GB of RAM, whilst the GPU processing was supplied by an NVIDIA Quadro6000 graphics card for each desktop. This setup was trialled previously by the team in two 


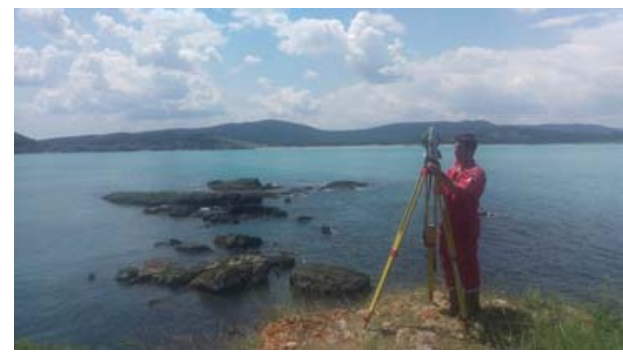

Fig. 8 Photograph showing the use of a Leica FlexLine TS06 plus to fix the static points of the trenches geographically (Photograph Michael Grant)

offshore survey campaigns on board MPSV Stril Explorer and then used similarly on board MPSV Havila Subsea during the Black Sea MAP expeditions of 2016 and 2017. Processing was done using Agisoft PhotoScan Pro version 1.3.2 build 4206.

A total of 80,128 images were captured between the 8 th and the 27th of June 2017. All of the processing was conducted overnight and it was automated using a python script, developed to run sequential photogrammetric workflows, which aligned the images, optimized the cameras, applied the pre-calibrated settings, built a dense cloud, generated a Delauney mesh, and computed a wrapping texture for the results to be revised prior to the next survey. From the 15 surveys done in Trench 1 the average number of images per survey was 2,263, 1,293 camera stations and 963,072 tie points. Trench 2 was surveyed 19 times and produced an average of 2,430 images per survey, 2,037 camera positions and 1,376,644 tie points. This produced a total of 58,124 photogrammetric alignments and 40,602,335 common points, or tie points, between the images. Covering a total of 25 square metres per survey at an average resolution of $0.223 \mathrm{~mm}$ per pixel $(1.13 \mu \mathrm{m} \times 1.13 \mu \mathrm{m})$ from an average altitude of 37.12 $\mathrm{cm}$ from the seabed.

\section{A. Georeferencing and Scaling}

Georeferencing of the photogrammetric 4D datasets was done by using the corners and junctions of the $2.5 \mathrm{~m}$ panels that formed the $5 \times 5 \mathrm{~m}$ trenches. Thanks to the shallow depth of the site it was possible to use a Leica FlexLine TS06 Plus total station 8 with a $3 \mathrm{~m}$ ranging pole with reflector to establish arbitrary $\mathrm{x}, \mathrm{y}, \mathrm{z}$ positions of the corners. The reflector was positioned vertically above the target and held in place by divers whilst the range and distance was taken by a surveyor from the shore from four different stations (see Fig. 8). Subsequently, each shoreline shore station was then assigned a geographic location using a real time kinematic (RTK) DGPS system to fix them into their respective geographic positions within the UTM $35 \mathrm{~N}$ zone.

4D modelling takes into account changes in space and time as dimensions to quantify changes. As the aim of the underwater excavation was to dissect the $5 \times 5 \mathrm{~m}$ trenches on a $100 \%$ coverage, recording accurately in time and space was key factor for success. Using the corners of the static panels of each of the trenches as constant points of reference proved to be a very effective way of keeping a common reference between the numerous surveys (Fig. 9). To increase

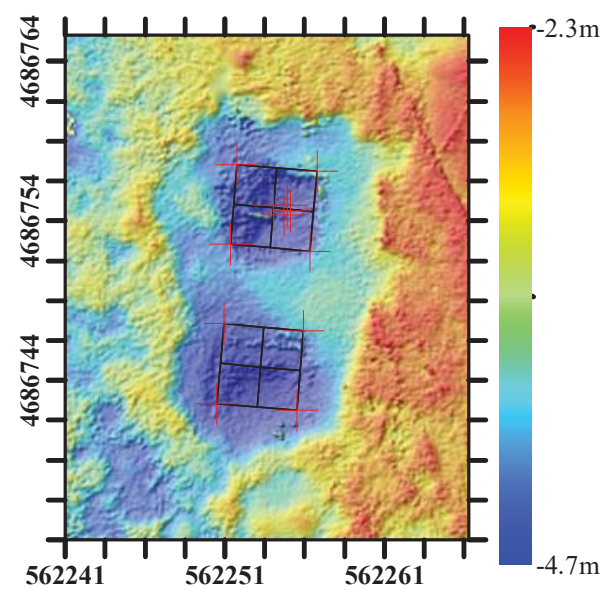

Fig. 9 Map showing the tie points used to scale and georectify the 4D photogrammetric datasets. The referenced point correlation with the multibeam survey can also be appreciated in the image. Depth is indicated in metres below Black Sea Mean Sea Level (BSMSL) (Image Rodrigo Pacheco-Ruiz)

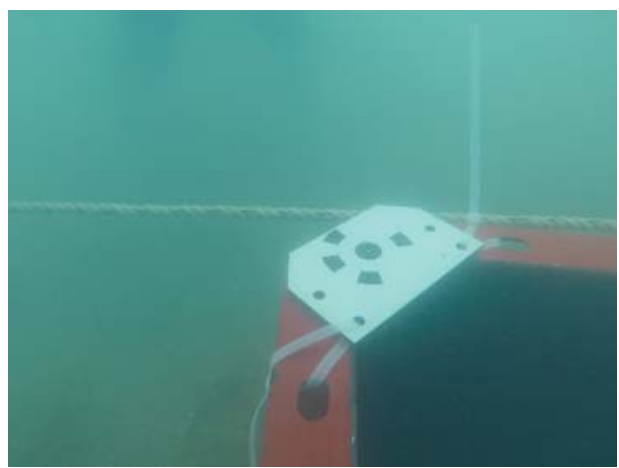

Fig. 10 Image showing the use of Agisoft Pgotoscan Pro markers for better automatic alignment in processing (Photograph Felix Pedrotti)

the possibilities of photogrammetric alignment using Agisoft Photo Scan Pro it was also decided to place Agisoft Photoscan Pro printed markers the inside faces of the panels and on the upper corners as seen in Fig. 10, as these are recognised automatically by the software. The panels therefore needed to be also part of the survey together with the excavated archaeological context. As the excavation progressed certain aspects of the archaeological context also functioned as additional tie points for scaling and geo-rectifying. One of such points was a Byzantine anchor similar to those found on the Tantura $F$ shipwreck dated to the first early-8th-century AD [16], [17](Fig. 11).

Scaling was established by inputting the known dimensions of the panels in each of the photogrammetric models. A second independent way of scaling the models was to trilaterate the interdistances between all the tags and determine their 3D coordinates using the Direct Survey Method (DSM) software used widely in maritime archaeology as a standard survey technique [18]. The third and final method was used as a safety-net-approach to scale and geo-reference the models, comparing the resulting 4D photogrammetric models with the imprint of the excavation evident on the swath bathymetric 


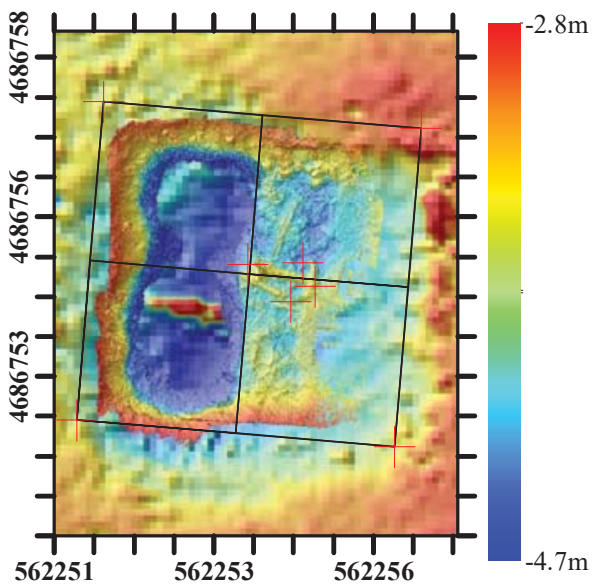

Fig. 11 Map showing the relationship and correlation between a single photogrammetric elevation model of trench 2 , the multibeam dataset and the reference points (red cross-hairs) tied and correlated using DSM and georeferenced using the total station. Depth is indicated in metres below

Black Sea Mean Sea Level (BSMSL) (Image Rodrigo Pacheco-Ruiz)

multi-beam survey of Ropotamo Bay conducted once the excavation operation concluded. Fig. 11 shows the correlation of the photogrammetric models and the multi-beam survey.

\section{B. The Working Datasets}

4D photogrammetric datasets of the Ropotamo 2017 underwater archaeological excavation therefore comprised of a combination of multi-proxy inputs. Primarily the spatial and temporal recording of each phase of the archaeological excavation using high resolution multi-source photogrammetry. Secondly the implementation of geo-location and scaling techniques to correlate such datasets in space and time by using RTK, total stations and DSM methodologies and comparing the results with the multi-beam swath bathymetric survey conducted at the end of the excavation programme.

Such combinations produced produced sixteen $3 \mathrm{D}$ records of trench 1 and 2, which when overlapped in time produced two 4D models of each trench. Figs. 12 and 13 show the results of the survey in each phase. It was clear for the team that the use of 4D modelling whilst on site had the advantage on focusing on the complexity of the archaeological record and less so on recording methodologies.

Many outcomes have been produced by the use of such datasets as interpretative tools. Firstly it was possible to quantify the rate of the excavation process, which enhances our documentation of any specific archaeological intervention and its subsequent analysis back in the lab. In other words, 4D modelling helps to keep track of the different excavation phases due to the rapid processing rate of data processing, which in turn allows for more informed decisions on managing and optimising field methodology. More significantly however, was the ability of study the archaeological context in far greater detail and better understand the nature of cultural deposition. Being able to revisit each stage of the excavation, in effect moving back and forth in time, significantly assisted our understanding of site formation processes in a hermeneutic

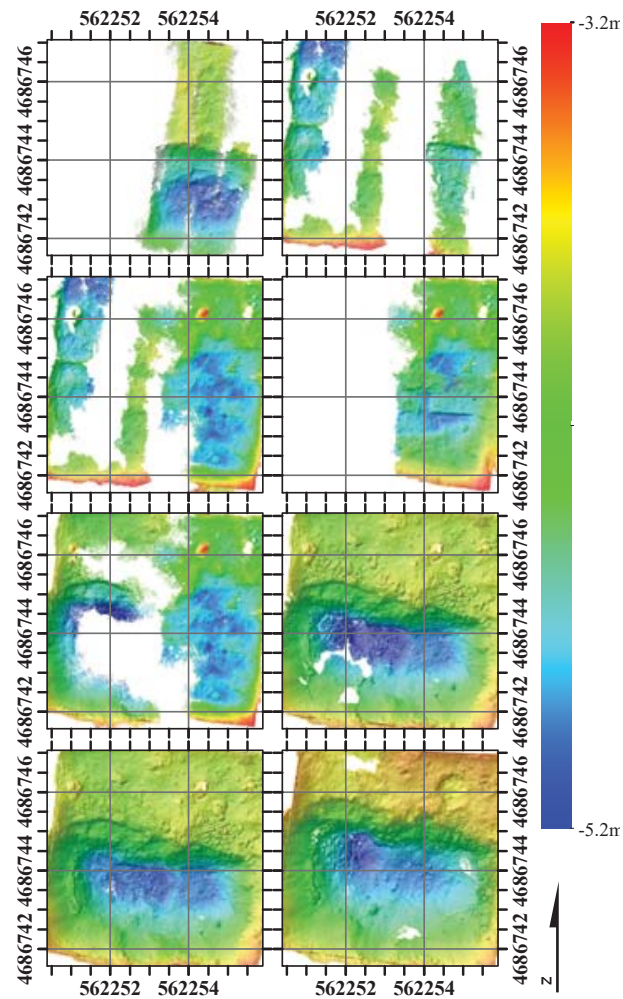

Fig. 12 Map showing the sequence of 3D models that form the 4D model of trench 1 from the underwater archaeological excavations of Ropotamo. From top left to bottom right are the 8th, 15th, 18th, 20th, 24th, 25th, 26th and 27th of June (Image Rodrigo Pacheco-Ruiz)

manner: Each layer revealed and modelled, enabled ideas to be developed and iteratively refined.

By using the results of 4D modelling as a hermeneutic tool it was possible to build a more detailed stratigraphic sequence of events, which in turn help explain the multi-period occupation of Ropotamo. A clear example of this is seen in Fig. 14, which shows the different stages of the excavation surrounding the Trench 2 Byzantine anchor. It is evident from our four-dimensional model that the anchor was deposited whilst the harbour was still in use, as the anchor can be seen to overlay of a dense layer of cultural material, predominantly ceramics, in phase one (Fig. 14a). Phase two of the anchor contextual sequence in Trench 2 shows a larger amount of ceramic material being deposited on top of the abandoned anchor, suggesting a continuous use of this area during the Byzantine Period (Fig. 14b). Finally, phase three shows the subsequent abandonment phase of the context as both the ceramics and the abandoned anchor are buried under a fine layer of marine sand (Fig. 14c). By virtually peeling off the layers of each excavation phase it was possible to understand deposition in a much more detailed manner than just recording the disturbance in the site before and after the excavation process.

\section{CONCLUSIONS}

This paper has demonstrated the applicability of photogrammetric recording under low visibility conditions of 


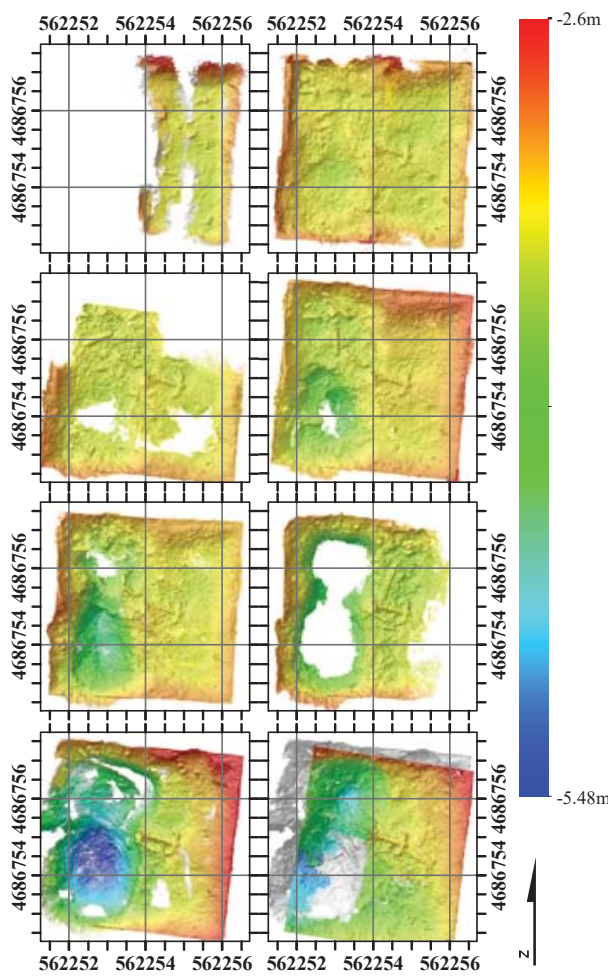

Fig. 13 Map showing the sequence of 3D models that form the 4D model of trench 2 from the underwater archaeological excavations of Ropotamo. From top left to bottom right are the 11th, 18th, 20th, 21st, 22nd, 23rd, 26th and 27th of June (Image Rodrigo Pacheco-Ruiz)

$<0.5 \mathrm{~m}$ to document the process of archaeological excavation underwater on a daily basis.

It argued for the use of such datasets to create spatio-temporal models to understand the complex nature of cultural material deposition. Such practice therefore, stems from the need for utilising four-dimensional datasets to produce interpretative tool-kits, which in turn aids the production of better informed archaeological decisions on site.

The underwater excavations at Ropotamo Bay in the Bulgarian Black Sea therefore demonstrate that four-dimensional recording of an archaeological site can bring multiple advantages in the production of archaeological information.

One of the most significant was the ability retrace the excavator's steps and revise methodology, technique and, most importantly, the relationship between archaeological elements in a multi-occupational site. The use of powerful computing and the collection of high resolution imagery therefore allows for a much richer spatio-temporal representation of the underwater archaeological excavation in challenging visibility conditions.

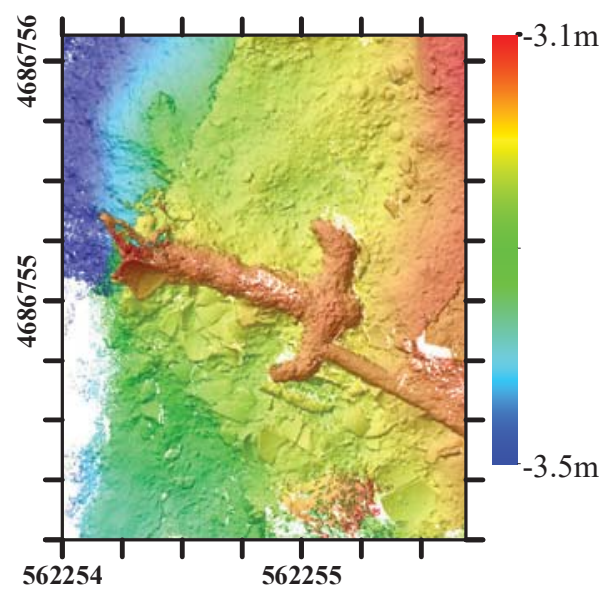

(a) Anchor lying on top of a layer of earlier ceramic material.

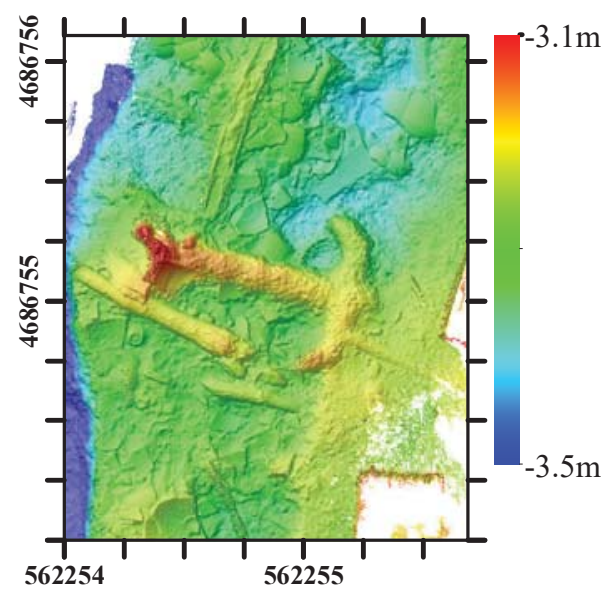

(b) Anchor with more material being accumulated on the sides and on top once this was deposited.

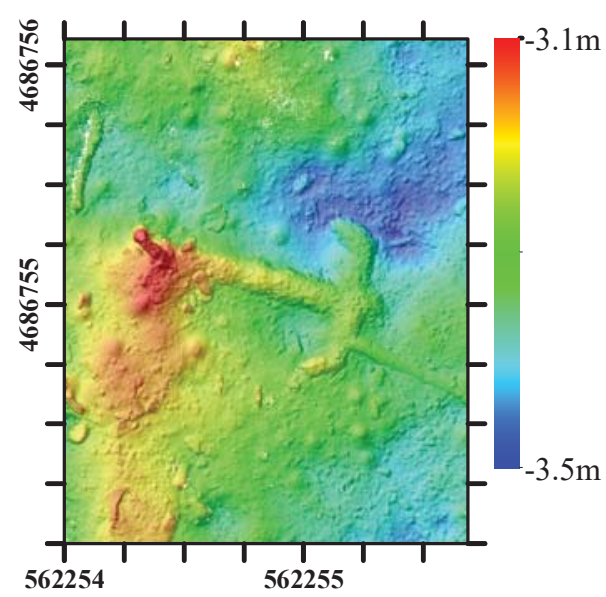

(c) Anchor and the associated archaeological material silted up by loose sand in the abandonment phases.

Fig. 14 Images showing the use of 4D photogrammetric modelling to understand depositional phases chronologically (Image Rodrigo Pacheco-Ruiz) 
The authors would like to thank the Julia and Hans Rausing Trust and their Education and Exploration Foundation (EEF) for their visionary funding and support of the Black Sea Maritime Archaeology Project and its excavation component at Ropotamo. The project team is built round a core partnership between the Centre for Maritime Archaeology, Southampton and the Centre for Underwater Archaeology, Sozopol, together with several partner institutions: the Maritime Archaeological Research Institute, Södertörn (MARIS), and the University of Connecticut. Industrial collaborators providing a platform for the development of methodology include MMT, CaTHX and Agisoft. The team is also grateful to all Bulgarian Authorities and Administrations who made the work possible.

\section{REFERENCES}

[1] G. F. Bass, “Archaeology Under Water," in Ancient peoples and places, New York, 1966.

[2] J. Green, "Maritime archaeology: a technical handbook," 1990.

[3] M. Rule, "The Mary Rose: The Excavation and Raising of Henry VIIIs Flagship," 1982.

[4] N. Rule, "Some techniques for cost-effective three-dimensional mapping of underwater sites," BAR International Series, vol. 598, p. 51, 1995.

[5] I. Karayotov, "The Antique and Medieval port at the mouth of the river Ropotamo," Acta TAB, vol. 5, pp. 64-66, 1990

[6] C. J. Lister, R. N. Hiscott, A. E. Aksu, and P. J. Mudie, "Compositional trends through the Holocene mud succession of the southwestern Black Sea shelf: Implications for sedimentary provenance and water-level history," Sedimentary Geology, vol. 316, pp. 13-25, 2015.

[7] G. Lericolais, J. Bourget, I. Popescu, P. Jermannaud, T. Mulder, S. Jorry, and N. Panin, "Late Quaternary deep-sea sedimentation in the western Black Sea: New insights from recent coring and seismic data in the deep basin," Global and Planetary Change, vol. 103, no. April 2013, pp. 232-247, apr 2013.

[8] H. Brückner, D. Kelterbaum, O. Marunchak, A. Porotov, and A. Vött, "The Holocene sea level story since 7500 BP Lessons from the Eastern Mediterranean, the Black and the Azov Seas," Quaternary International, vol. 225, no. 2, pp. 160-179, oct 2010.

[9] V. Yanko-Hombach, A. S. Gilbert, and P. Dolukhanov, "Controversy over the great flood hypotheses in the Black Sea in light of geological, paleontological, and archaeological evidence," Ouaternary International, vol. 167-168, pp. 91-113, jun 2007

[10] I. Popescu, G. Lericolais, N. Panin, A. Normand, C. Dinu, and E. Le Drezen, "The Danube submarine canyon (Black Sea): morphology and sedimentary processes," Marine Geology, vol. 206, no. 1-4, pp. 249-265, may 2004.

[11] A. E. Aksu, H. Gillespie, and P. J. Mudie, "Dino flagellate cysts , freshwater algae and fungal spores as salinity indicators in Late Quaternary cores from Marmara and Black seas," vol. 190, 2002.

[12] A. E. Aksu, R. N. Hiscott, and D. Ya, "Oscillating Quaternary water levels of the Marmara Sea and vigorous outflow into the Aegean Sea from the Marmara Sea Black Sea drainage corridor," vol. 153, pp. 275-302, 1999.

[13] W. B. F. Ryan, W. C. Pitman, C. Major, K. Shimkus, V. Moskalenko, G. A. Jones, P. Dimitrov, N. Goriir, M. Saking, and H. Yiice, "An abrupt drowning of the Black Sea shelf," vol. 138, pp. 119-126, 1997.

[14] J. McCarthy and J. Benjamin, "Multi-image Photogrammetry for Underwater Archaeological Site Recording: An Accessible, Diver-Based Approach," Journal of Maritime Archaeology, mar 2014.

[15] C. Beltrame and E. Costa, "3D survey and modelling of shipwrecks in different underwater environments," Journal of Cultural Heritage, 2017

[16] O. Barkai and Y. Kahanov, "The Tantura F Shipwreck, Israel," International Journal of Nautical Archaeology, vol. 36, no. 1, p. 21, 2007.

[17] M. Eliyahu, O. Barkai, Y Goren, N. Eliaz, Y Kahanov, and D. Ashkenazi, "The iron anchors from the Tantura F shipwreck: typological and metallurgical analyses," Journal of Archaeological Science, vol. 38, no. 2, pp. 233-245, 2011.

[18] N. Rule, "The Direct Survey Method (DSM) OF Underwater Survey, And Its Application Underwater," International Journal of Nautical Archaeology, vol. 18, no. 2, pp. 157-162, 1989.

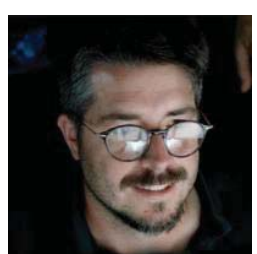

Rodrigo Pacheco-Ruiz received his $\mathrm{PhD}$ from the University of Southampton in 2015. He is a specialist in maritime archaeology, with interests in coastal societies and their interaction with the changing environment. $\mathrm{He}$ is also interested in developing new ways of exploring and documenting remote deep sea archaeological sites.

His experience in this field has been extensive and varied, participating in a number of commercial and research international projects in the Mediterranean, the North Atlantic Ocean, the Baltic, the English Channel, the Persian Gulf and the Black Sea, as well as inland water sites in the British Isles and Mexico.

$\mathrm{He}$ is currently working on prehistoric maritime landscapes and 15th 18th Century shipwrecks of North and Eastern Europe using state-of-the-art technologies and computational modelling.

Rodrigo is a member of staff at the Centre for Maritime Archaeology of the University of Southampton and full time research fellow on the Black Sea Maritime Archaeology Project (Black Sea MAP) led by Professor Jon Adams and funded by EEF Expeditions.

$\mathrm{He}$ is also involved on external collaboration with the Prehistory, Ancient History, Archaeology and Geography Research Group from the Universidade de Santiago de Compostela in Spain dedicated in particular on the maritime aspects of prehistoric Atlantic communities as well as collaboration with the Institute of Anthropologic Studies from the UNAM in Mexico. Rodrigo is a Nautical Archaeology Society tutor as well as a HSE Air Commercial Diver.

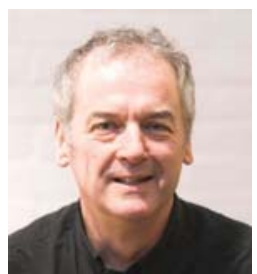

Jonathan Adams is a Professor of Maritime Archaeology and Founding Director of the University of Southampton's Centre for Maritime Archaeology. He trained at Durham and Stockholm Universities and his research interests centre on the processes of innovation and social change, particularly as evidenced through the technology of ship building and seafaring. He also has a long term interest in the ethics as well as the theory and methods of deep water archaeology. $\mathrm{He}$ became involved in maritime archaeology through the Mary Rose Project where, as a Deputy Director of Archaeology, he co-superintended the professional diving operations in the salvage and recovery phase. He went on to direct several other underwater excavations including the Sea Venture Project in Bermuda, the Amsterdam Project in the UK (with Prof Jerzy Gawronski) and the Kravel Project in Sweden (with Prof Johan Rönnby). As well as the Black Sea Maritime Archaeology Project, he is currently working on projects in the UK, the Baltic and the Channel Islands. He is the Founding Editor of the Journal of Maritime Archaeology.

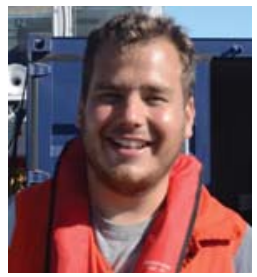

Felix Pedrotti is a $\mathrm{PhD}$ candidate in archaeology at the University of Southampton and his main interest covers the relationship and interactions between a riverscape and its fluvial communities. In addition to this interest, he invested a few years in the study of ancient cultures and their languages, especially Latin, Ancient Greek, Hittite and Hieroglyphics. Furthermore, he has a strong interest in the application of photogrammetry to record and survey archaeological sites and their contents. This has led to his work in integrating photogrammetric models into virtual reality environments, exploring the ways in which these can be used as research tools but also as shared virtual spaces either in museums or on personal platforms.

In recent years Felix has participated in various commercial and research international projects across the globe, from excavations in Italy, Croatia, Bulgaria and the Adriatic Sea, to multi-purposed surveys in the United Kingdom, the Black Sea, the North Atlantic Ocean and the English Channel. Currently he is working on the use of photogrammetry and its combination with geophysical data. Felix holds a HSE SSDE qualification and is a CMAS 2 Instructor. 